\title{
Characterising the space-time structure of rainfall in the Sahel with a view to estimating IDAF curves
}

\author{
G. Panthou, T. Vischel, T. Lebel, G. Quantin, and G. Molinié \\ LTHE - UMR5564, Univ. Grenoble, IRD, CNRS, Grenoble, France \\ Correspondence to: T. Vischel (theo.vischel@ujf-grenoble.fr)
}

Received: 30 June 2014 - Published in Hydrol. Earth Syst. Sci. Discuss.: 23 July 2014

Revised: 3 November 2014 - Accepted: 3 November 2014 - Published: 11 December 2014

\begin{abstract}
Intensity-duration-area-frequency (IDAF) curves are increasingly demanded for characterising the severity of storms and for designing hydraulic structures. Their computation requires inferring areal rainfall distributions over the range of space scales and timescales that are the most relevant for hydrological studies at catchment scale. In this study, IDAF curves are computed for the first time in West Africa, based on the data provided by the AMMA-CATCH Niger network, composed of 30 recording rain gauges having operated since 1990 over a $16000 \mathrm{~km}^{2}$ area in south-western Niger. The IDAF curves are obtained by separately considering the time (intensity-duration-frequency, IDF) and space (areal reduction factor, ARF) components of the extreme rainfall distribution. Annual maximum intensities are extracted for resolutions between 1 and $24 \mathrm{~h}$ in time and from point (rain gauge) to $2500 \mathrm{~km}^{2}$ in space. The IDF model used is based on the concept of scale invariance (simple scaling) which allows the normalisation of the different temporal resolutions of maxima series to which a global generalised extreme value (GEV) is fitted. This parsimonious framework allows one to use the concept of dynamic scaling to describe the ARF. The results show that coupling a simple scaling in space and time with a dynamical scaling that relates to space and time allows one to satisfactorily model the effect of space-time aggregation on the distribution of extreme rainfall.
\end{abstract}

\section{Introduction}

Torrential rain and floods have long been a major issue for hydrologists. For one, defining and computing their probability of occurrence is a scientific challenge per se, largely because it is a scale-dependent exercise. Second, and equally important, is the fact that they cause heavy environmental, societal, and economical damages - including human casualties - thus being a major concern for populations and decision makers.

The request of providing both an objective assessment of the probability of occurrence of high-impact rainfall and a tool for civil engineering structure design has found an answer through the calculation of intensity-duration-frequency (IDF) curves. These curves, generally computed from raingauge data, are intended to characterise the evolution of extreme rainfall distributions at a point when the duration of rainfall accumulation changes. However, rainfall at point location is not of the greatest interest when it comes to the hydrological and socio-economic impacts of extreme events, since it is essentially the convolution of the rainfall intensities over a catchment that characterises the severity of storms and creates the real threat.

This is why intensity-duration-area-frequency (IDAF) curves were conceived as a spatial extension of the IDF curves. Generally established by combining IDF curves and areal reduction factors (ARFs), they provide an estimation of extreme areal rainfall quantiles over a range of timescales and spatial scales.

Theoretical studies on IDF and ARFs have been an active research topic over the past 20 years or so (Koutsoyiannis et al., 1998; Menabde et al., 1999; De Michele et al., 2001, 2011, among others). IDF practical studies are also numerous but focused on regions where long series of sub-daily rainfall are available (e.g. Borga et al., 2005; Gerold and Watkins, 2005; Nhat et al., 2007; Bara et al., 2009; Ben-Zvi, 2009; Overeem et al., 2009; Awadallah, 2011; Ariff et al., 2012). On the other hand, when ARFs are computed from 
rain-gauge networks (Bell, 1976; Asquith and Famiglietti, 2000; Allen and DeGaetano, 2005), it requires a fair density of rain gauges in order to obtain accurate estimates of areal rainfall. The computation of IDAF curves must therefore deal with two major data requirements: (i) a high-density network of rain gauges and (ii) an array of long sub-daily rainfall series. In addition to these requirements, scientists face the challenge of producing coherent ARF and IDF models, if they wish for their IDAF model to be statistically consistent. This explains why there are so few studies dealing with the implementation of an IDAF model over a given region (e.g. De Michele et al., 2002, 2011; Castro et al., 2004; Ceresetti, 2011).

In fact, in some regions of the world there are virtually no IDF, ARF, and IDAF models that have ever been conceived because of data limitations. This is especially the case in many tropical regions, such as West Africa; in fact, one reason being that a harsh environment and resource scarcity have made it very challenging to operate recording raingauge networks. The few IDF studies available in the region (Oyebande, 1982; Mohymont et al., 2004; Oyegoke and Oyebande, 2008; Soro et al., 2010) are essentially empirical with no theoretical background that allows for the upgrade of their results in order to produce IDAF curves. ARF studies are still fewer, the most noticeable being an attempt by Rodier and Ribstein (1988) and Ribstein and Rodier (1994) at computing ARF values for a return period of 10 years, with no explicit inference of the areal rainfall distributions. All in all, there has never been any IDAF model derived for West Africa or sub-regions of West Africa. Yet, flood management - for which IDAF curves are a very useful tool - is now a major concern for West African countries. As a matter of fact and despite that West Africa is known for having experienced a major lasting drought over 1970-2000, numerous severe floods and exceptional inundations have struck the region over the last 2 decades (Tarhule, 2005; Descroix et al., 2012; Samimi et al., 2012). Moreover, flood damages in the region have been constantly increasing since 1950 (DiBaldassarre et al., 2010).

While operational networks of the West African National Weather Services do not allow the establishment of IDAF curves in a consistent way - because they do not provide any long-term sub-daily rainfall series - there are other sources of data that can be used for that purpose. Among them are the 5 min rainfall series of the long-term AMMA-CATCH observing system covering a $16000 \mathrm{~km}^{2}$ area in south-western Niger from 1990 to present (Fig. 1). In this study we will make use of 30 series providing continuous 5 min rainfall records from 1990 to 2012.

This unique data set enables us to characterise the relationship between extreme rainfall distributions computed at various spatio-temporal scales and to propose IDAF curves for this characteristic Sahelian region.
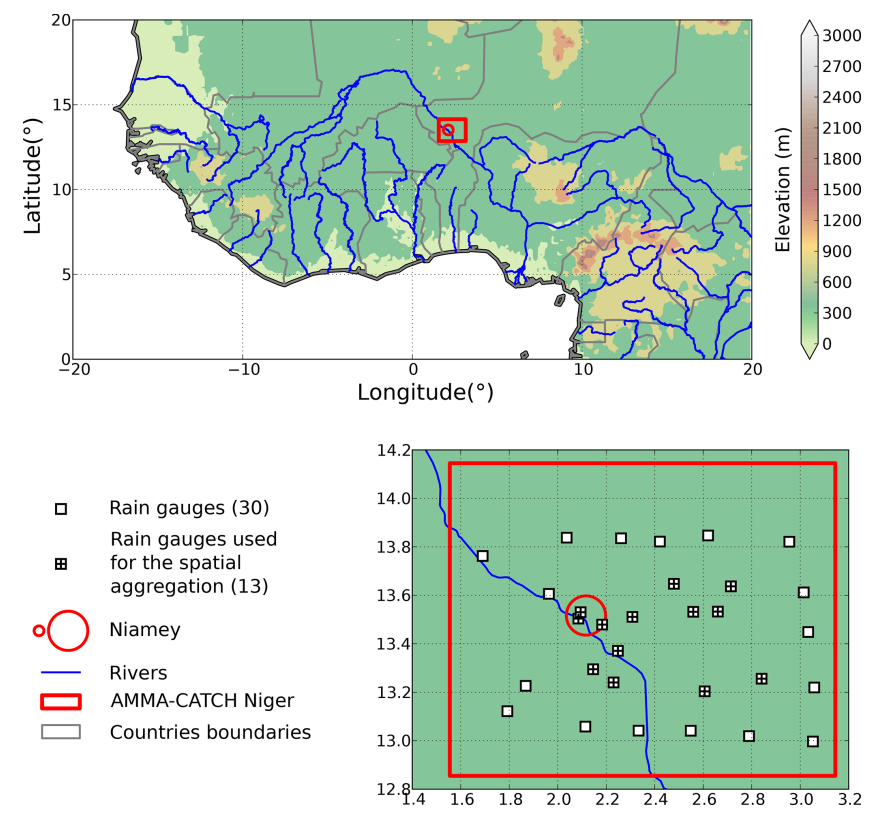

Figure 1. Study area. The background maps displays the elevation (metres).

\section{IDAF curves in a generalised extreme value distribu- tion and scale invariance framework}

IDAF curves provide an estimate of areal rain rates - averaged over a given duration $D$ and a given area $A-$ for a given frequency of occurrence (currently expressed in term of return period $T_{\mathrm{r}}$ ). In practice, IDAF curves are generally obtained by aggregating a temporal component and a spatial component represented respectively by the IDF computed at a point $(A=0)$ and by the ARF computed for a range of durations. In this framework, the most general formulation of an IDAF equation is as follows:

$\operatorname{IDAF}\left(D, A, T_{\mathrm{r}}\right)=\operatorname{IDF}\left(D, T_{\mathrm{r}}\right) \times \operatorname{ARF}\left(D, A, T_{\mathrm{r}}\right)$.

Assessing IDAF curves requires (i) inferring appropriate statistical distributions of rainfall to estimate the return periods and (ii) describing the statistical links between the distributions obtained at different space scales and timescales.

Several recent studies have confirmed that the generalised extreme value (GEV) distribution (Coles, 2001) provides a suitable framework to describe the distribution of extreme rainfall at a point (e.g. Overeem et al., 2008; Panthou et al., 2012; Papalexiou and Koutsoyiannis, 2013). Also, many authors have shown that rainfall displays scale invariance properties (Schertzer and Lovejoy, 1987; Gupta and Waymire, 1990; Burlando and Rosso, 1996; Bendjoudi et al., 1997; Veneziano et al., 2006), both in space and time. The temporal scaling properties give access to a direct analytical formulation of IDF curves (Menabde et al., 1999; Borga et al., 2005; Ceresetti, 2011), while the spatial scaling properties allow one to upscale IDF curves into IDAF curves (De Michele 
et al., 2002, 2011; Castro et al., 2004), thus providing an integrated space-time characterisation of extreme rainfall distributions. Under certain assumptions, namely the GEV distribution of point annual rainfall maxima and simple scaling in both time and space, an analytical formulation of the various components of Eq. (1) may be obtained, as will be detailed below.

\subsection{GEV distribution}

Let us define $I(D, A)$ as a random variable representing the annual maxima of rainfall accumulated over a given duration $D$ and area $A$, and $i(D, A)$ a sample of $I(D, A)$. In the general framework of the block maxima sampling scheme (Coles, 2001), working on annual maxima generally ensures that the block size is large enough for the maxima distribution to follow a GEV distribution (Coles, 2001), written as

$G(i ; \mu, \sigma, \xi)=\exp \left\{-\left[1+\xi\left(\frac{i-\mu}{\sigma}\right)\right]^{-\frac{1}{\xi}}\right\}$

for $1+\xi\left(\frac{i-\mu}{\sigma}\right)>0$,

where $i$ is a generic notation for any value associated with a realisation of $I(D, A), \mu$ being the location parameter, $\sigma>$ 0 the scale parameter, and $\xi$ the shape parameter of the GEV distribution. The shape parameter describes the behaviour of the distribution tail: a positive (negative) shape corresponds to a heavy-tailed (bounded) distribution. When $\xi$ is equal to 0 , the GEV reduces to the Gumbel distribution (light-tailed distribution):

$G(i ; \mu, \sigma)=\exp \left\{-\exp \left[-\left(\frac{i-\mu}{\sigma}\right)\right]\right\}$.

\subsection{Simple scaling in time and analytical formulation of IDF curves}

The simple-scaling framework has been extensively used for deriving IDF curves (Menabde et al., 1999; Yu et al., 2004; Borga et al., 2005; Nhat et al., 2007; Bara et al., 2009; Ceresetti, 2011). An analytical formulation of the ARF was also given by Veneziano and Langousis (2005) in a multi-scaling framework. However, simple scaling is much more tractable than the multi-scaling approach and is more robust in terms of parameter inference; thus, this is the approach chosen here.

The annual maximum point rainfall random variable $\{I(D, 0)\}$ follows a simple-scaling relation for a given duration $D$ (with respect to a reference duration $D_{\text {ref }}$ ) if

$I(D, 0) \stackrel{d}{=} \lambda^{\eta} \times I\left(D_{\mathrm{ref}}, 0\right)$,

where $\lambda$ is a scale ratio $\left(\lambda=D / D_{\text {ref }}\right), \eta$ is a scale exponent, and $\stackrel{d}{=}$ denotes an equality in distribution. Note that, for every duration $D$ for which Eq. (4) holds, the normalised random variable $\left\{I(D, 0) / D^{\eta}\right\}$ has the same statistical distribution as the normalised reference distribution $\left\{I\left(D_{\text {ref }}, 0\right) / D_{\text {ref }}^{\eta}\right\}$; this property will be used in the optimisation procedure in Sect. 4.2. Equation (4) implies (Gupta and Waymire, 1990)

$E[I(D, 0)]=\lambda^{\eta} \times E\left[I\left(D_{\text {ref }}, 0\right)\right]$

and, more generally, a scaling of all the moments that can be written as

$E\left[I^{q}(D, 0)\right]=\lambda^{k(q)} \times E\left[I^{q}\left(D_{\mathrm{ref}}, 0\right)\right]$

or

$\ln \left\{E\left[I^{q}(D, 0)\right]\right\}=k(q) \ln (\lambda)+\ln \left\{E\left[I^{q}\left(D_{\text {ref }}, 0\right)\right]\right\}$.

The notion of simple scaling is related to how $k(q)$ evolves with $q$. When this evolution is linear

$k(q)=\eta q$

and simple scaling holds (as opposed to multi-scaling if this relation in non-linear).

Checking whether the simple-scaling hypothesis is admissible over a given range of durations is thus equivalent to verifying through the data set whether the two following conditions are fulfilled (Gupta and Waymire, 1990):

- Eq. (7): $\log -\log$ linearity between the statistical moments of any given order $q$

- Eq. (8): linearity between $k(q)$ and $q$.

Figure 2a illustrates these two conditions.

\subsection{Spatial scaling, dynamical scaling, and ARF model}

In its most general sense, the ARF is the ratio between areal rainfall and point rainfall, either for a given observed rain event or in a statistical sense. Here we are interested in deriving a statistical ARF that can be used for obtaining an analytical formulation of IDAF curves (which implies that the ARF does not depend on the return period considered); thus, this ARF denotes the ratio between the areal distribution and the point distribution of the annual rainfall maxima:

$I(D, A) \stackrel{d}{=} \operatorname{ARF}(D, A) \times I(D, 0)$.

Note that Eq. (9) implies the following relationship:

$\operatorname{ARF}(D, A)=\frac{E[I(D, A)]}{E[I(D, 0)]}$.

In this study, the ARF model proposed by De Michele et al. (2001) is used. This model is based on two assumptions (which will have to be verified; see Sect. 5):

1. The studied rainfall variable is characterised by a simple-scaling relationship both in time and space. 
a)

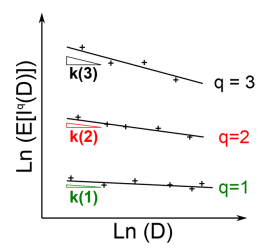

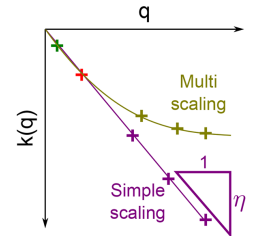

b)

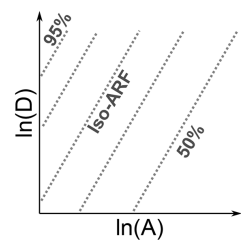

Figure 2. Visual model checks: (a) simple scaling; (b) ARF.

2. Time and spatial scales are linked by a so-called dynamic-scaling property written as

$\left(\frac{D}{D_{\text {ref }}}\right)=\left(\frac{A}{A_{\text {ref }}}\right)^{z}$

where $z$ is the dynamic-scaling exponent.

When these assumptions are verified, De Michele et al. (2001) show that the ARF can be written as

$\operatorname{ARF}(D, A)=\left[1+\omega\left(\frac{A^{a}}{D^{b}}\right)\right]^{\eta / b}=\left[1+\omega\left(\frac{A^{z}}{D}\right)^{b}\right]^{\eta / b}$,

where $\eta$ is the scaling exponent characterising the temporal simple scaling, $a$ and $b$ are two positive constant-scaling exponents linked by the relation $z=a / b$, and $\omega$ is a factor of normalisation.

This ARF formulation implies that iso-ARFs are lines in the plane $\{\ln (A), \ln (D)\}$ as shown in Fig. $2 \mathrm{~b}$ (De Michele et al., 2001).

\subsection{GEV simple-scaling IDAF model}

By assuming that the maximum annual rainfall is GEVdistributed and that the scaling relations in time and space (Sects. 2.2 and 2.3) are verified, then the IDAF model is

$I(D, A) \stackrel{d}{=} I\left(D_{\mathrm{ref}}, 0\right) \times \lambda^{\eta} \times \operatorname{ARF}(D, A)$.

As shown in the Appendix A, the compatibility of the simple-scaling and GEV frameworks is defined by the following equations:

$$
\begin{aligned}
& I(D, A) \sim \operatorname{GEV}\{\mu(D, A), \sigma(D, A), \xi(D, A)\} \\
& \mu(D, A)=\mu_{\text {ref }} \times \lambda^{\eta} \times \operatorname{ARF}(D, A) \\
& \sigma(D, A)=\sigma_{\text {ref }} \times \lambda^{\eta} \times \operatorname{ARF}(D, A) \\
& \xi(D, A)=\xi_{\text {ref }}
\end{aligned}
$$

where $\mu_{\text {ref }}, \sigma_{\text {ref }}$, and $\xi_{\text {ref }}$ correspond to the GEV parameters computed for the arbitrary reference duration $D_{\text {ref }}$ at a point, and $\lambda=D / D_{\text {ref }}$.

\section{Data and implementation}

Rainfall observing systems usually do not provide direct measurements at all the space scales and timescales required for an IDAF study; thus, it is necessary to derive from the raw data set an elaborated data set that allows one to verify the various assumptions found in the theoretical framework defined in Sect. 2.

Accordingly, this section describes both the rainfall samples initially available on our Sahelian region of southwestern Niger and the process used to obtain the final data set from which the IDAF curves were computed. This process consists of two major steps:

1. space-time aggregation of the $5 \mathrm{~min}$ point rain rates in order to obtain the average rain rates for various space $(A)$ and time $(D)$ resolutions

2. extraction of extreme rainfall samples for each of the above resolutions.

\subsection{The rainfall data set: AMMA-CATCH Niger records}

The AMMA-CATCH Niger observing system was set up at the end of the 1980s as part of the long-term monitoring component of the HAPEX-Sahel experiment (Lebel et al., 1992). Since then, it has continuously operated a large array of meteorological and hydrological instruments, providing a unique set of high-resolution hydrometeorological data, covering a $16000 \mathrm{~km}^{2}$ area in south-western Niger. For the purpose of this research, a subset of thirty 5 min rainfall series was selected (Fig. 1), covering the entire 1990-2012 period. At each station, all years with more than $25 \%$ of missing data have been removed in order to limit any sampling effect due to missing data in a particular year. After this quality control, all stations remain with at least 20 years of valid data, constituting our raw data sample.

To estimate areal rainfall intensities, this study makes use of the dynamical kriging interpolation method proposed by Vischel et al. (2011). Rain fields are produced over the domain of study at a time resolution of $5 \mathrm{~min}$ and a spatial resolution of $1 \mathrm{~km}^{2}$. Dynamical kriging takes advantage of the time structure of $5 \mathrm{~min}$ rain fields to complement the purely spatial information provided by the gauge network. Instead of using a 3-D variogram (the inference of the space-time cross-covariance being notoriously non-robust), the method relies on the construction of Lagrangian rain fields which display a stable spatial structure represented by a nested exponential variogram. Dynamical kriging is an exact interpolator in the sense that the measured point values are replicated exactly; this interpolator is then used to produce $5 \mathrm{~min}$ rainfall grids, with a grid mesh of $1 \mathrm{~km}^{2}$. 


\subsection{Space-time rainfall aggregation}

The starting elements of the space-time aggregation process are the discretized fields of rain accumulated over a time increment $\Delta t=5 \mathrm{~min}$ and averaged over a square pixel of side length $\Delta x y=1 \mathrm{~km}$. In the following, these rain fields are denoted as $r^{*}\left(x^{*}, y^{*}, t^{*}\right)$, where $t^{*}$ is the ending time of the 5 min time step, and $\left\{x^{*}, y^{*}\right\}$ is the centre of the $1 \mathrm{~km}^{2}$ pixel.

\subsubsection{Spatial aggregation of $5 \mathrm{~min}$ rain fields}

Let $A$ be a surface over which the rainfall intensity is averaged. In this study, $A$ is a square of side $N x \times \Delta x y \mathrm{~km}=$ $N y \times \Delta x y \mathrm{~km}$ (corresponding to $N x \times N y$ pixels of $1 \mathrm{~km}^{2}$ ). From the 5 min rain fields we can compute series of space averaged 5 min rain field accumulations, $r_{\mathrm{A}}^{*}$, as

$r_{\mathrm{A}}^{*}\left(x^{*}, y^{*}, t^{*}\right)=\frac{1}{A} \sum_{m=0}^{N x-1} \sum_{n=0}^{N y-1} r^{*}$

$\left\{x^{*}+\left(m-\frac{N x-1}{2}\right) \Delta x y, y^{*}+\left(n-\frac{N y-1}{2}\right) \Delta x y, t^{*}\right\}$.

From these spatially averaged rain fields, spatial rainfall series have been extracted at rain-gauge locations. For each rain-gauge location (located at $\{x, y\}$ ), the nearest spatial rainfall series, $r_{\mathrm{A}}^{*}$ (located at $\left\{x^{*}, y^{*}\right\}$ ), is extracted. Figure $3 \mathrm{a}$ illustrates this approach the black circle of the right panel represents a rain-gauge located at $\{x, y\}$. In total, 12 scales of spatial aggregations have been retained to build the rainfall series: $1 \mathrm{~km}^{2}$ (the pixel on which the station is located is selected) then $4,9,16,25,49,100,225,400,900$, 1600 , and $2500 \mathrm{~km}^{2}$.

To limit border effects, the spatial aggregation is performed only in areas where the spatial distribution of stations is more or less isotropic. Each of the 30 measurement stations are considered individually; a circle centred on the station is plotted and divided in eight cardinal sectors (each sector has an angle of $45^{\circ}$ ). Only rain gauges having at least one other rain gauge present in at least seven of the eight sectors are retained for spatial aggregation (see Fig. 3a); the distance of the other gauges from the centre station is not taken into account for the selection, only the presence or absence of a rain gauge in the sector. Only 13 gauges (out of 30) satisfy this criterion (Fig. 1). They are referred to in the following as a central rain gauge (CR) because their localisation is used as a central point, from which the 12 areas of aggregation are delimited. In total there are thus 156 areal series (12 areas of aggregation centred on 13 different locations).

\subsubsection{Time aggregation of $5 \mathrm{~min}$ point series and $5 \mathrm{~min}$ spatial series}

A time aggregation procedure is applied to the 30 point $5 \mathrm{~min}$ rainfall series and to the 156 spatial rainfall series.

Let $D$ be a given duration of $N t 5 \mathrm{~min}$ time steps $(D=$ $N t \times \Delta t$ ). The time aggregation is done by using a moving a)

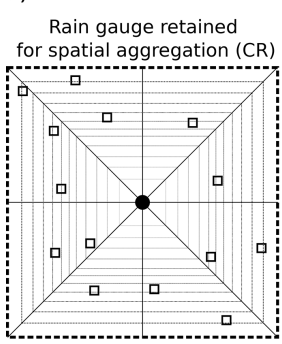

Rain gauge not retained for spatial aggregation

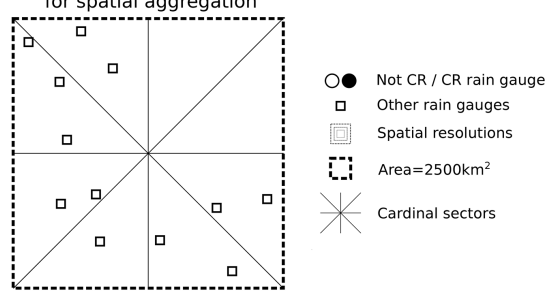

b)

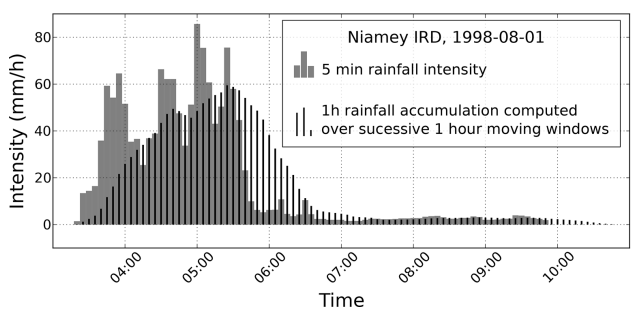

Figure 3. Space and time aggregation procedures. (a) Illustration of the procedure leading to select (right case) or to reject (left case) a gauge for becoming a centre for spatial aggregation; (b) time aggregation at a point: comparing a hyetograph of $5 \mathrm{~min}$ rainfall to a hyetograph of $1 \mathrm{~h}$ rainfall.

time window of length $D$ over which the 5 min rainfall intensity is averaged (this moving window procedure is carried out in order to make sure that we will be able to extract the maximum for each duration considered). The time aggregation can be written as

$r_{D, 0}^{*}\left(x, y, t^{*}\right)=\frac{1}{D} \sum_{p=0}^{N t-1} r_{0}^{*}\left(x, y, t^{*}-p \times \Delta t\right)$

in the case of $5 \mathrm{~min}$ point series located at $\{x, y\}(A=0)$, and

$r_{D, A}^{*}\left(x^{*}, y^{*}, t^{*}\right)=\frac{1}{D} \sum_{p=0}^{N t-1} r_{\mathrm{A}}^{*}\left(x^{*}, y^{*}, t^{*}-p \times \Delta t\right)$

for a given surface $A$ in the case of 5 min spatial rainfall series located at $\left\{x^{*}, y^{*}\right\}$.

Thus, $N t=12$ for $D=1 \mathrm{~h}, N t=24$ for $D=2 \mathrm{~h}$ and so forth. This procedure is illustrated in Fig. 3b. The 11 different time resolutions considered in this study range from 1 to $24 \mathrm{~h}$ $(1,2,3,4,6,8,10,12,15,18$, and $24 \mathrm{~h})$ and are all obtained from the original 5 min series.

\subsubsection{Extraction of extreme rainfall: annual block maxima}

The use of GEV distribution to model the extreme rainfall series requires using the block maxima procedure to extract rainfall extremes. It consists of defining annual blocks of observations separately for each of the 11 different time resolutions considered and to take the maxima within each block. 
A sample of 23 (1990-2012) annual maximum rainfall values $\{i(D, A)\}$ is thus obtained for each spatial aggregation and duration.

In summary

- There are 13 reference locations.

- Around each of the 13 reference locations, 12 areas of increasing size $1,4,9,16,25,49,100,225,400,900$, 1600 , and $2500 \mathrm{~km}^{2}$ are defined.

- For each of these $156(13 \times 12)$ areas, 11 time series of 23 (1990-2012) annual maximum values are constructed, corresponding to 11 different durations of rainfall accumulation 1, 2, 3, 4, 6, 8, 10, 12, 15, 18, $24 \mathrm{~h}$.

\section{Inferences of the individual components of the model}

The proposed model has seven parameters: the temporal scale exponent $(\eta)$, the three ARF parameters $(a, b, \omega)$, and the three GEV parameters $\left(\mu_{\text {ref }}, \sigma_{\text {ref }}, \xi_{\text {ref }}\right)$. After having tested different optimisation procedures (most notably a global maximum likelihood estimation and the two-step method proposed by Koutsoyiannis et al., 1998), a three-step method was finally retained, since it gave the best results in the evaluation of the IDAF model (see Sect. 5). These three steps are explained in the following paragraphs (Sects. 4.1 to 4.3). For each step, an illustration based on the result obtained for the Niamey Aéroport station is given in Fig. 4.

\subsection{Temporal simple scaling: estimation of $\eta$}

The temporal scaling of the IDAF model is described by the $\eta$ parameter. The inference of $\eta$ is achieved in two steps. The first one consists of computing $k(q)$ for different moments $q$ through a linear regression between the logarithm of the statistical moments of order $q\left(E\left[I^{q}\right]\right)$ and the durations $D$ (see Fig. 4a, left panel); next, $\eta$ is obtained by a linear regression between $k(q)$ and $q$ (see Fig. 4a, right panel). At the Niamey Aéroport station, the value obtained for $\eta$ is equal to -0.91 .

\subsection{GEV parameters: $\mu_{\text {ref }}, \sigma_{\text {ref }}, \xi_{\text {ref }}$}

The GEV parameters $\mu_{\text {ref }}, \sigma_{\text {ref }}, \xi_{\text {ref }}$ are estimated on the point samples, using the property that all normalised samples $\left\{i(D, 0) / D^{\eta}\right\}$ must come from the same distribution if simple scaling holds. All normalised samples are pooled in one single sample on which the GEV parameters are estimated (this methodology corresponds to the second step of the two-step method proposed by Koutsoyiannis et al., 1998). Figure $4 \mathrm{~b}$ illustrates this process at the Niamey Aéroport rain gauge: initial samples are displayed on the left panel normalised samples are plotted on the right panel. The fitted GEV and the estimated GEV parameters are also given in this figure.
In comparison with fitting the GEV parameters separately to each sample constituted for each duration, this method aims at limiting sampling effects by fitting the GEV parameters on a single sample gathering all rainfall durations. The maximum likelihood and the L-moments methods were tested for estimating the GEV parameters. The estimation provided by these methods gave similar results, probably due to the large sample size. The results of the L-moments method are presented here, while this method is generally considered better than the Maximum Likelihood Estimation (MLE) for the estimation of high quantiles when the length of the series is short (Hosking and Wallis, 1997).

\subsection{Spatial scaling}

The estimation of $a, b$, and $\omega$ was carried out by minimising the mean square difference between the empirical ARF (Eq. 10) and the model ARF (Eq. 12), as originally proposed by De Michele et al. (2001). Other scores (mean and max. absolute error, bias, etc.) and variables (difference between the observed and model mean areal rainfall) have been tried but gave poorer results in validation (Sect. 5). Figure $4 \mathrm{c}$ shows the comparison between the empirical ARF and the model ARF at the Niamey Aéroport station and the parameters obtained for the theoretical ARF model.

\subsection{Regional model}

The point parameter inference ( $\mu_{\text {ref }}, \sigma_{\text {ref }}, \xi_{\text {ref }}$ and $\eta$ ) has been performed on each of the 30 point rainfall series, which thus provide 30 IDF models. The complete IDAF model has been fitted to each of the 13 rain gauges CR. The obtained IDF and IDAF parameters display neither any coherent spatial pattern nor any trend over the domain, as may be seen in Fig. 5. Sampling effects due to the small area and the short length of the series may explain this point, since a trend has been observed on a larger domain at the regional scale for daily rainfall (Panthou et al., 2012).

Assuming a spatial homogeneity of rainfall distribution (no spatial pattern), annual maxima series have been pooled together to obtain regional samples. The regional samples were used to fit the IDAF model over the domain in order to limit sampling effects. The point regional sample pools together the 30 rainfall samples directly provided by the 30 rain gauges $i(D, 0)$; the 12 areal regional samples obtained for each of the 12 spatial resolutions $\{i(D, A) ; A=$ $\left.1, \ldots, 2500 \mathrm{~km}^{2}\right\}$ result from pooling together the 13 individual series (CRs) computed as explained in Sect. 3.

Table 1 presents the parameters obtained for the global IDAF model. The obtained GEV parameters are $\mu_{\text {ref }}=40.6 \mathrm{~mm} \mathrm{~h}^{-1}, \quad \sigma_{\text {ref }}=10.8 \mathrm{~mm} \mathrm{~h}^{-1}$, and $\xi_{\text {ref }}=0.1$. When upscaled to the daily duration $\mu(24 \mathrm{~h})=2.29 \mathrm{~mm} \mathrm{~h}^{-1} \quad\left(55.0 \mathrm{~mm} \mathrm{day}^{-1}\right) \quad$ and $\sigma(24 \mathrm{~h})=0.61 \mathrm{~mm} \mathrm{~h}^{-1} \quad\left(14.6 \mathrm{~mm} \mathrm{day}^{-1}\right)$. It is worth noting that these latter values are coherent with those 
a)

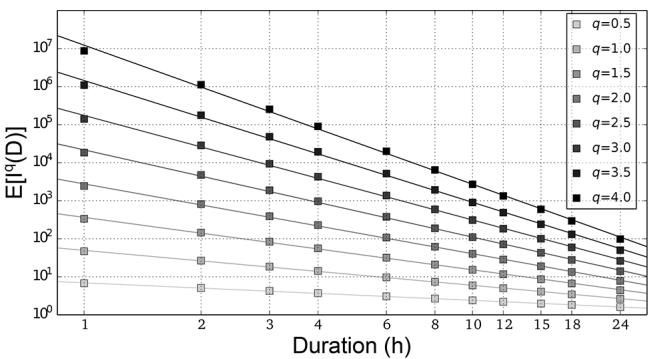

b)

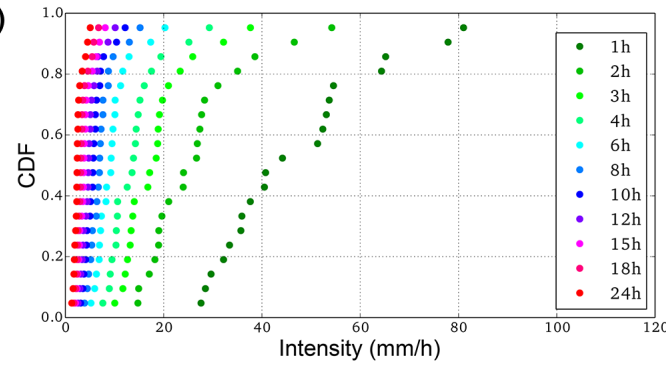

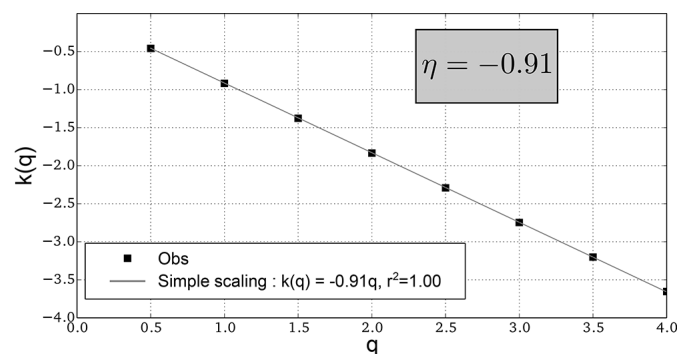

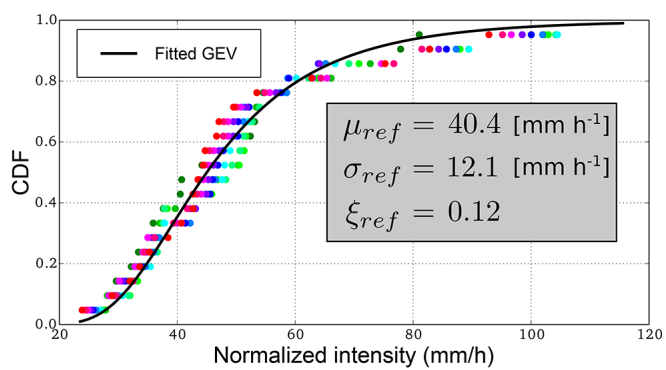

c)

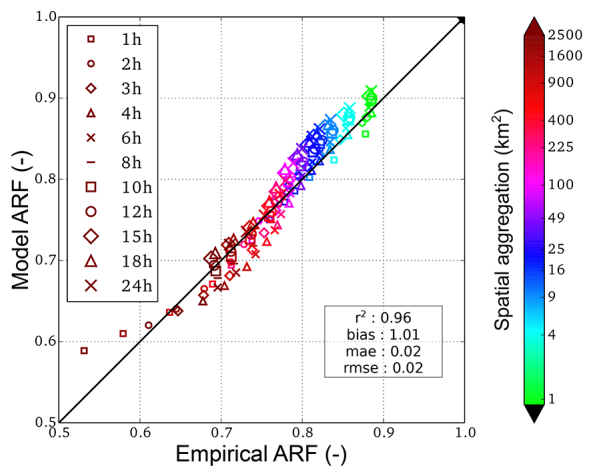

$$
\begin{gathered}
\omega=0.02 \\
a=0.14 \\
b=0.11
\end{gathered}
$$

Figure 4. Example of IDAF model inference at the Niamey Aéroport rain gauge: (a) checking of the temporal simple-scaling conditions (left: linear relationship between the logarithm of the statistical moments of order $q$ and the durations $D$, right: linear relationship between $k(q)$ and $q$ ) and estimation of the temporal simple-scaling exponent; (b) left: empirical cumulative distribution of annual maxima, right: global fitting of the GEV parameters; (c) comparison between empirical and modelled ARF.

\begin{tabular}{|c|c|c|c|c|c|c|c|c|c|c|c|}
\hline & (a) $\mu_{\mathrm{ref}}$ & $\sigma_{\text {ref }}$ & $\xi$ & $\eta$ & $a$ & $b$ & $z$ & $\omega$ & & & \\
\hline & 40.60 & 10.81 & 0.10 & -0.90 & 0.165 & 0.156 & 1.06 & 0.02 & & & \\
\hline (b) GEV parameter & $1 \mathrm{~h}$ & $2 \mathrm{~h}$ & $3 \mathrm{~h}$ & $4 \mathrm{~h}$ & $6 \mathrm{~h}$ & $8 \mathrm{~h}$ & $10 \mathrm{~h}$ & $12 \mathrm{~h}$ & $15 \mathrm{~h}$ & $18 \mathrm{~h}$ & $24 \mathrm{~h}$ \\
\hline$\mu\left(\mathrm{mm} \mathrm{h}^{-1}\right)$ & 40.60 & 21.68 & 15.02 & 11.58 & 8.02 & 6.19 & 5.05 & 4.29 & 3.50 & 2.97 & 2.29 \\
\hline$\sigma\left(\mathrm{mm} \mathrm{h}^{-1}\right)$ & 10.81 & 5.77 & 4.00 & 3.08 & 2.14 & 1.65 & 1.35 & 1.14 & 0.93 & 0.79 & 0.61 \\
\hline$\xi(-)$ & \multicolumn{11}{|c|}{0.10} \\
\hline
\end{tabular}

Table 1. Obtained parameters for the global IDAF model (a) and corresponding GEV parameter values for the different durations $D$ for the point scale $A=0$ (b).

obtained for a much larger area in this region by Panthou et al. (2012, 2013), working on the data of 126 daily rain gauges covering the period 1950-1990. Note also that the temporal scale exponent $(\eta)$ is large $(0.9)$, which means that the intensity strongly decreases as the duration increases. This is not surprising given the strong convective nature of rainfall in this region. Similar values of the temporal scaling exponents are obtained in regions where strong convective systems occur (Mohymont et al., 2004; Van-de Vyver and Demarée, 2010; Ceresetti et al., 2011), while lower values are obtained in regions where extreme rainfall is generated by different kinds of meteorological systems (for example 

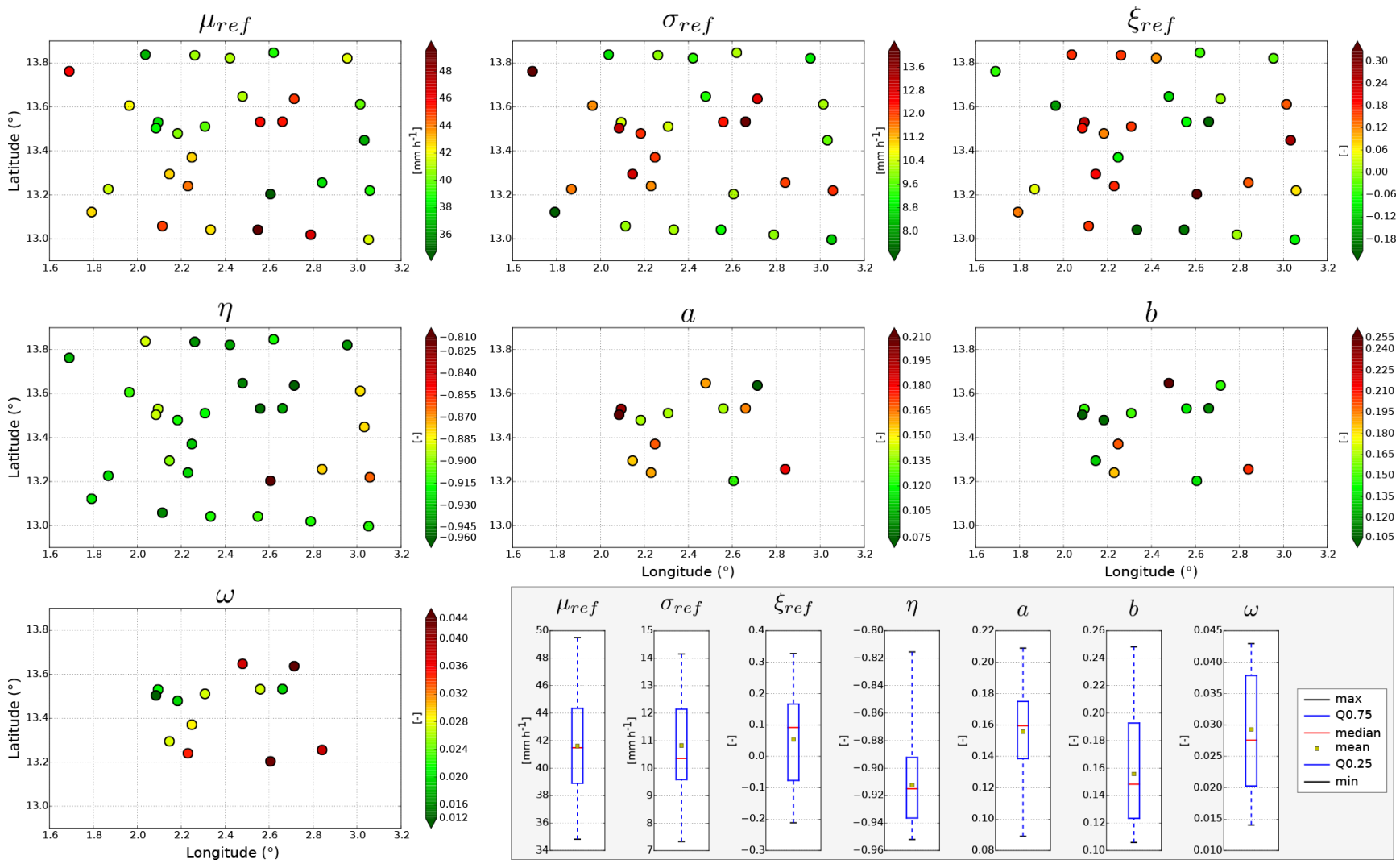

Figure 5. Map of the obtained IDF parameters $\left(\eta, \mu_{\text {ref }}, \sigma_{\text {ref }}\right.$, and $\xi_{\text {ref }}$ fitted on the 30 rain gauge samples $)$ and IDAF parameters $\left(\eta, \mu\right.$ ref,$\sigma_{\text {ref }}$ $\xi_{\text {ref }}, a, b$, and $\omega$ fitted on the $13 \mathrm{CR}$ samples). The grey box shows box plots of the parameter values obtained at the different rain gauges.

in many mid-latitude regions; see e.g. Menabde et al., 1999; Borga et al., 2005; Nhat et al., 2007). The dynamic-scaling exponent is roughly equal to 1 which means that increasing the surface by a given factor leads to a similar ARF change than increasing the duration by the same factor (keeping in mind that this rule applies only to the range of time-space resolutions explored here).

\section{IDAF model evaluation}

The evaluation of the IDAF model is carried out in two successive stages. First each component used to build the final model (temporal simple scaling, ARF model, and GEV distribution) is checked individually; next, the global goodness of fit (GOF) is tested using the Anderson-Darling (AD) and the Kolmogorov-Smirnov (KS) tests.

In Fig. 6 two series of graphs are plotted in order to verify whether the simple-scaling hypothesis holds for the time dimension. On the left are the plots of $\ln \left(E\left[I^{q}\right]\right)$ vs. $\ln (D)$ designed to check the $\log -\log$ linearity between these two variables (Eq. 7); on the right are the plots of $q$ vs. $k(q)$ aimed at checking the linearity between these two variables (Eq. 8). At all three spatial scales, there is a clear linearity of the plots, meaning that the two conditions for accepting the temporal simple-scaling hypothesis are fulfilled. Note that the graphs shown are those obtained on the regional samples for three different spatial scales only (point scale, 100 and $2500 \mathrm{~km}^{2}$ ), but the quality of the fitting is similar for all the other spatial scales.

Simple scaling in space and dynamical scaling (e.g. the relationship between time and spatial scaling) are checked in Fig. 7. This figure compares the empirical ARFs (Eq. 10) computed on the regional samples and the ARFs obtained with the model (Eq. 12) for all the space scales and timescales pooled together. With a determination coefficient $\left(r^{2}\right)$ of 0.98 , and a very small root mean square error, it appears that the model restitutes very well the empirical ARF at all space scales and timescales, except at the hourly time step and for the three largest surfaces $\left(900,1600\right.$, and $\left.2500 \mathrm{~km}^{2}\right)$, for which the model significantly underestimates the observed reduction factor. At such space scales and timescales the finite size of the convective systems generating the rain fields creates a significant external intermittency (see Ali et al., 2003, on the distinction between internal and external intermittency). It thus seems that the simple-scaling framework holds only as long as the influence of the external intermittency is negligible or weak. Consequently, it is likely that the overestimation of the ARF by the simple scaling- 
$A=$ point
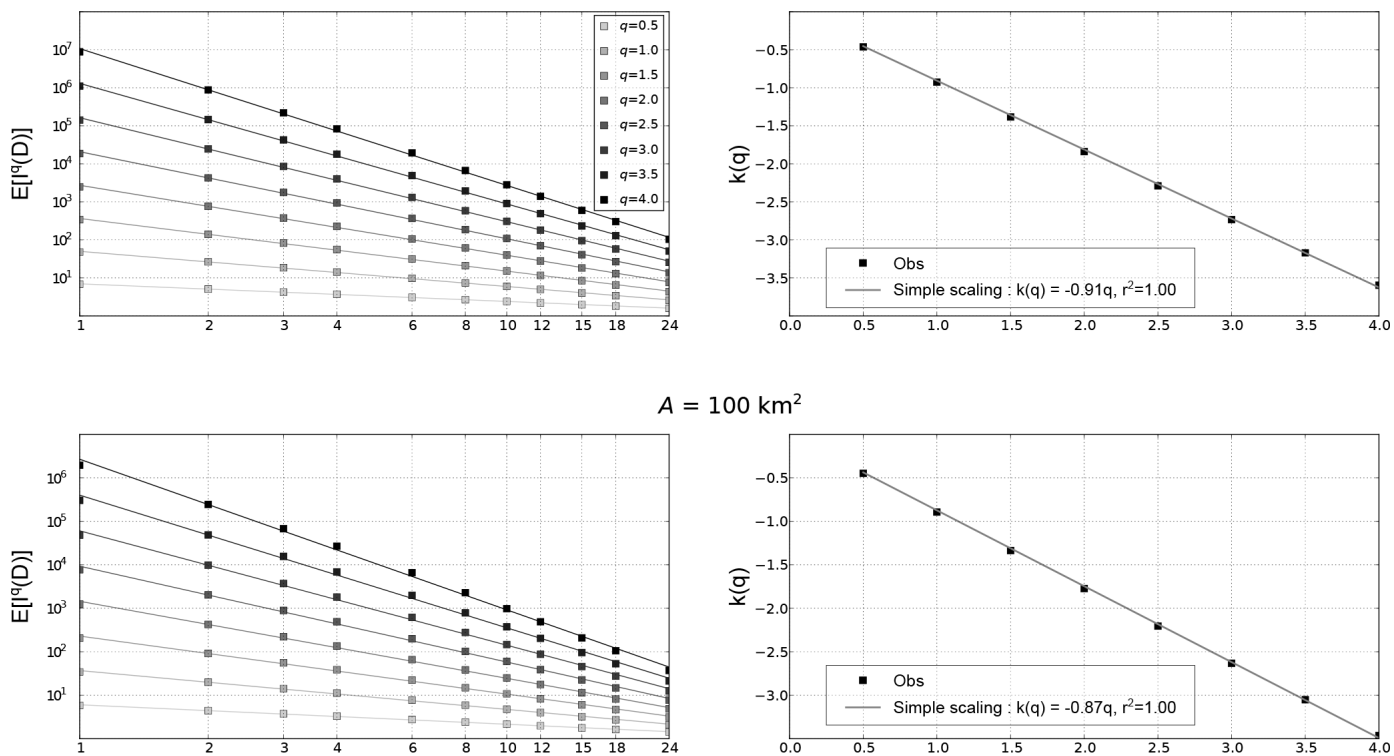

$A=100 \mathrm{~km}^{2}$

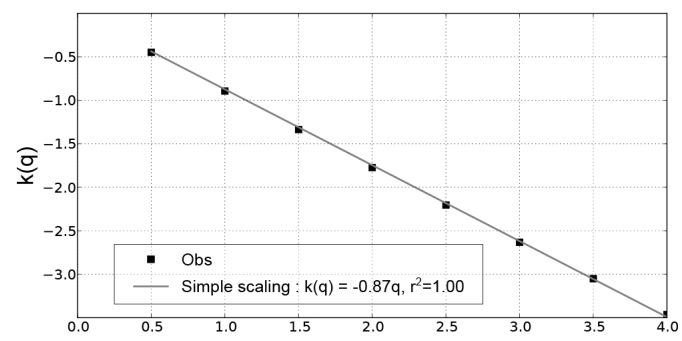

$A=2500 \mathrm{~km}^{2}$
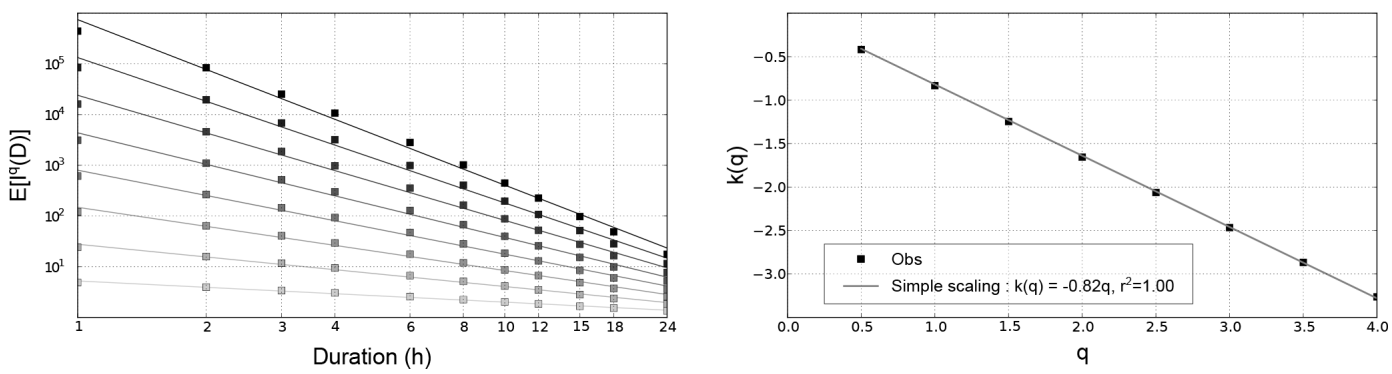

Figure 6. Checking of the temporal simple-scaling conditions for the regional samples defined by the 30 available rain gauges for point resolution (top), and the $13 \mathrm{CRs}$ (see Sect. 3.2.1) for resolutions at $100 \mathrm{~km}^{2}$ (middle) and $2500 \mathrm{~km}^{2}$ (bottom).

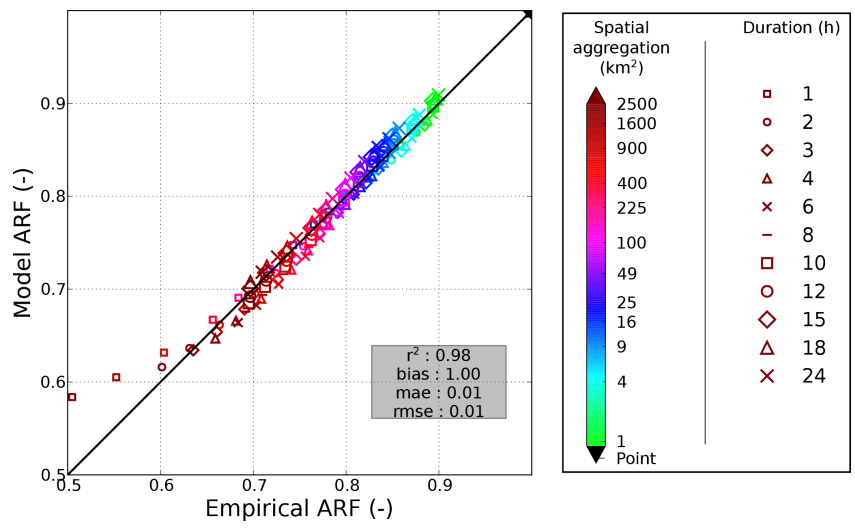

Figure 7. Comparison between empirical ARF (obtained with the regional samples: 30 rain gauges for point resolution and $13 \mathrm{CRs}$ for other spatial resolutions) and the modelled ARF IDAF model. based model would be observed for larger space scales and timescales than the ones the AMMA-CATCH data set allows one to explore.

Figure 8 illustrates that the global model is also able to reproduce very correctly the mean areal rainfall intensity over the whole time-space domain explored here, except again for the hourly time step and the largest surfaces.

As the IDAF model is primarily designed to estimate high quantiles, its ability to represent the mean is not a sufficient skill. It is thus of primary importance to evaluate its ability to also represent correctly high return levels and extreme quantiles. This was realised by visually inspecting return level plots and by using GOF statistical tests computed in a crossvalidation mode (all the stations are used to calibrate the model except one which is used to validate the model prediction). These tests are used to quantitatively assess how well the theoretical GEV distribution based on the IDAF model fits the empirical Cumulative Distribution Functions (CDF) of the observed annual maxima for each spatio-temporal resolution. Each test provides a statistic and its corresponding 


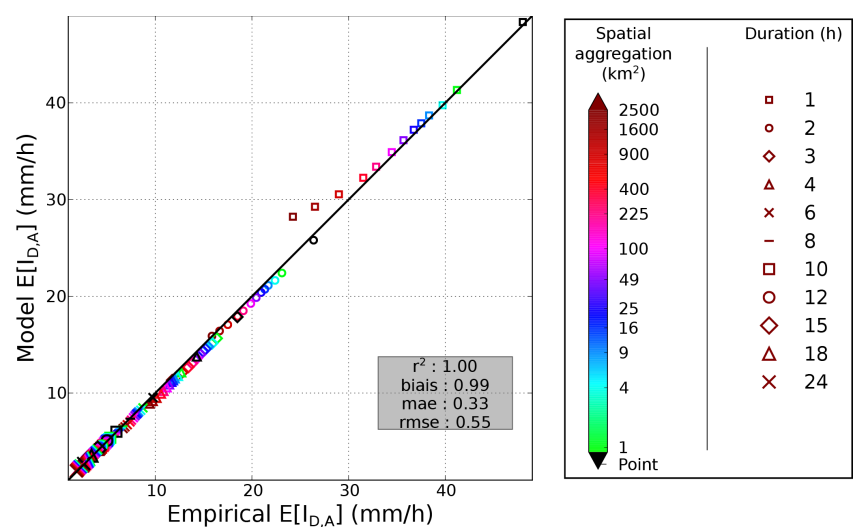

Figure 8. Comparison between empirical mean areal rainfall intensity (obtained with the regional samples: 30 rain gauges for point resolution and $13 \mathrm{CRs}$ for other spatial resolutions) and global IDAF model for different spatio-temporal aggregations.

$p$ value. The $p$ value is used as an acceptation/rejection criterion by fixing a threshold of non-exceedance (here 1,5 , and $10 \%)$.

The return level plots displayed in Fig. 9 for two reference locations and three time steps allow a visual inspection of the capacity of the global IDAF to fit the empirical samples. The $p$ values of the two GOF tests are given in the inset caption. As could be expected, there is a significant dispersion of the results obtained on individual samples. The difficulty of reproducing correctly the empirical distribution when combining the smallest time steps with the largest areas is confirmed. While similar graphs were plotted for the other 11 reference locations, it is obviously difficult to obtain a relevant global evaluation from the visual examination of such plots.

Figure 10 aims at tackling this limitation by representing this information in a more synthetic way. In this figure the percentage of individual series for which the IDAF model is rejected by the AD GOF test is mapped for each duration and spatial aggregation for two levels of significance (1 and $10 \%)$. Here it is worth remembering that we have 30 individual series for the point scale, and 13 different individual series for each of the 12 spatial scales, meaning that, for a given time step, the percentage of rejections/acceptations are computed from a total of $186(30+12 \times 13)$ test values. Here again, the limits of the model for small time steps and large areas are clearly visible; one can also notice a larger number of rejections for small areas and the highest durations (duration higher than $12 \mathrm{~h}$ and area smaller than $25 \mathrm{~km}^{2}$ ). Apart from that, the number of rejections of the null hypothesis remains low. The KS test (not shown) displays similar results with fewer rejections of the null hypothesis. It thus appears fair to conclude that, over the range of space scales and timescales covered by the AMMA-CATCH network, a simple scaling approach allows for computing realistic ARFs, the limit of validity being reached for areas roughly larger than $1000 \mathrm{~km}^{2}$ at the hourly time step.

\section{Discussion and conclusions}

Up to now the rarity of rainfall measurements at high spacetime resolution in tropical Africa has not allowed comprehensive studies on the scaling properties of rain fields in that region to be carry out. From 1990 the recording rain-gauge network of the AMMA-CATCH observing system has sampled rainfall in a typical Sahelian region of West Africa at a time resolution of $5 \mathrm{~min}$ and a space resolution of $20 \mathrm{~km}$, over an area slightly larger than $1^{\circ} \times 1^{\circ}$. This data set was used here for characterising the space-time structure of extreme rainfall distribution, the first time such an attempt has been made in this region where rainfall is notoriously highly variable.

Simple scaling was shown to hold for both the time and the space dimensions over a space-time domain ranging from 1 to $24 \mathrm{~h}$ and from the point scale to $2500 \mathrm{~km}^{2}$; it was further shown that dynamical scaling relates the timescales to the space scales, leading to propose a global IDAF model valid over this space-time domain, under the assumption that extreme rainfall values are GEV distributed.

Different optimisation procedures were explored in order to infer the seven parameters of this global IDAF model. A three-step procedure was finally retained, the global IDAF model being fitted to a global sample built from all the different samples available for a given space scales and timescale. This model has been evaluated through different graphical methods and scores. These scores show that the ARFs yielded by the IDAF model fit significantly well (in a statistical sense) with the observed ARFs over our space-time domain, except for the part of the domain combining the smallest timescales with the largest space scales. This limitation is likely related to the larger influence of the external intermittency of the rain fields at such space scales and timescales.

Despite the growing accuracy of rainfall remote-sensing devices, this study demonstrates that dense rain-gauge networks operating in a consistent way over long periods of time are still keys to the statistical modelling of extreme rainfall. In the numerous regions where rainfall is undersampled by operational networks and where satellite monitoring is not accurate enough to provide meaningful values of high rainfall at small space scales and timescales, dense networks covering a limited area may provide the information necessary for complementing the operational networks and satellite monitoring. In West Africa, south of the Niger site, AMMA-CATCH has been operating another site of similar size in a Sudanian climate since 1997 (Ouémé Catchment, Benin), providing ground for a similar study in a more humid tropical climate.

As mentioned in the discussion of Sect. 5, there is however a limitation of these two research networks, linked to their spatial coverage. Extending the area sampled by these networks to something of the order of $2^{\circ} \times 2^{\circ}$ would indeed allow for studying more finely the effect of the limited size of the convective systems onto the statistical properties of 
Niamey Aeroport
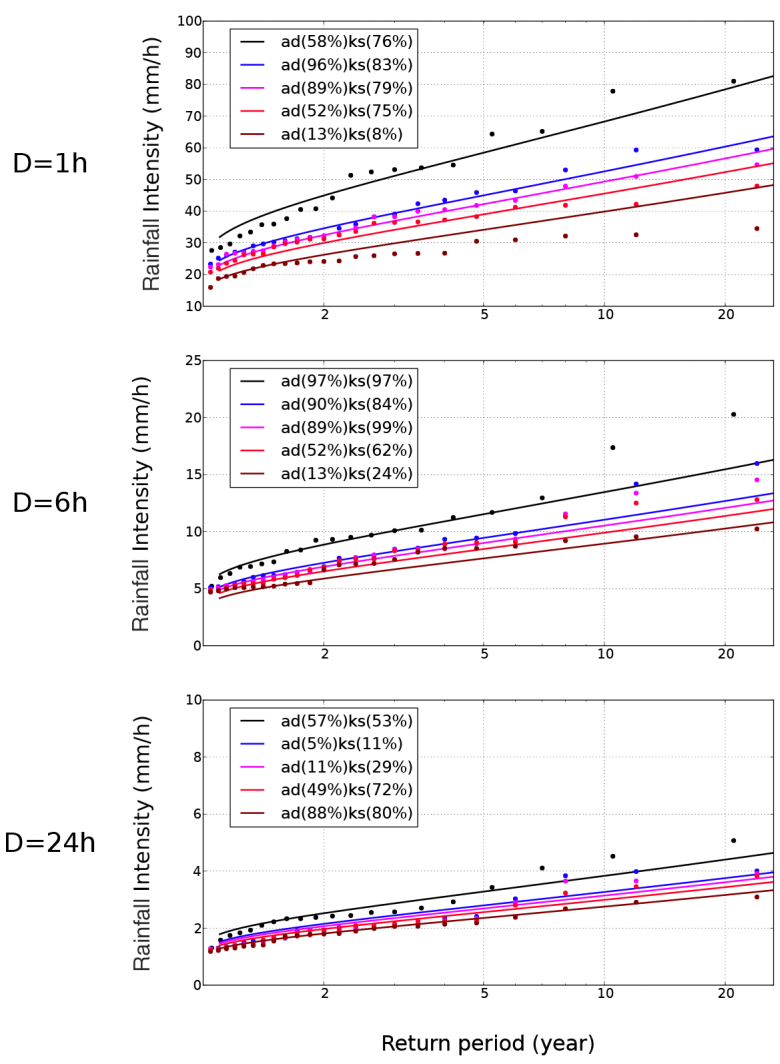

Niamey IRD
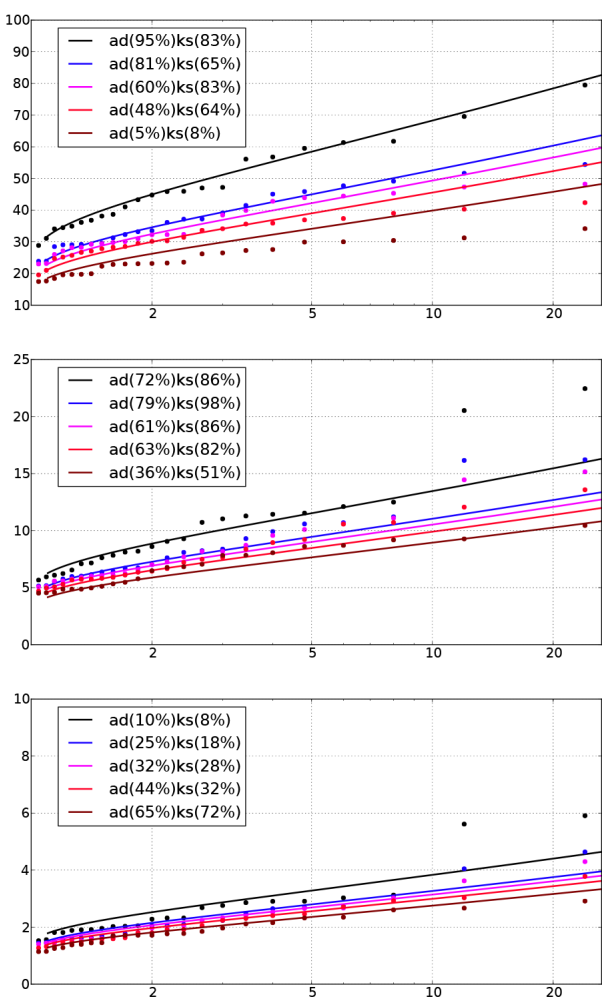

Return period (year)

Spatial Aggregation $\left(\mathrm{km}^{2}\right)$

$$
\text { - } 0 \text { (point) }-25-100-400-2500
$$

Figure 9. Empirical return level plot obtained at two rain gauges in comparison with the global IDAF model for different durations ( $1 \mathrm{~h}, 6 \mathrm{~h}$, and $24 \mathrm{~h}$ from top to bottom) and different spatial aggregations (from point to $2500 \mathrm{~km}^{2}$ ).

a)

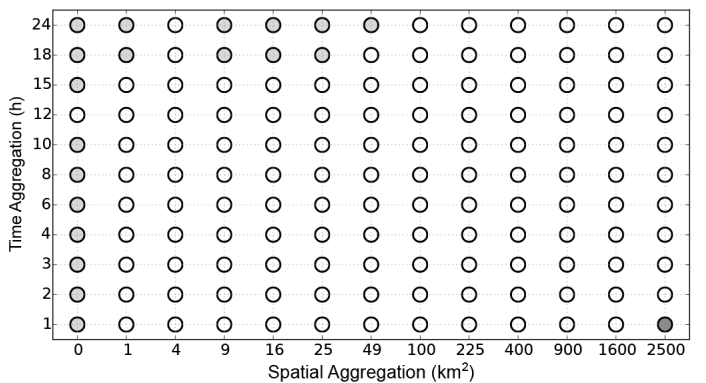

b)

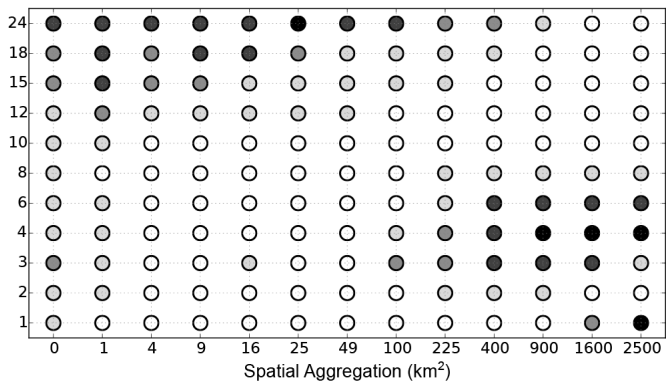

\begin{tabular}{|c|c|c|c|c|}
\hline \multicolumn{5}{|c|}{ Percentage of rejected series } \\
\hline ○ $0 \%$ & O ] $0-10 \%$ ] & O ] $10-20 \%$ ] & - ] ]20-40\% ] & - $>40 \%$ \\
\hline
\end{tabular}

Figure 10. Anderson-Darling GOF test (cross-validation): percentage of rejected series for $1 \%$ (a) and $10 \%$ (b) significance level for the global IDAF model. Note that there are 30 series for the point scale $\left(0 \mathrm{~km}^{2}\right)$ and 13 for the other spatial aggregation (CR). 
the associated rain fields. However, this means enlarging the area by a factor of 4 , making it much more costly and difficult from a logistical point of view to survey properly. For the years to come, AMMA-CATCH remains committed to operating both the Niger and the Benin sites for documenting possible evolutions of the rainfall regimes at fine space scales and timescales in the context of global change as well as for verifying whether the scaling relationships proposed here still hold for quantiles at higher time periods. As a matter of fact, one strong hypothesis of the model proposed here is that the ARF is independent of the return period. This hypothesis seems verified for return periods smaller than the length of our time series, but it is not possible to infer whether this really holds for higher return periods. Therefore, developing an IDAF model able to account for a possible evolution of the ARF with the return period level is a path that has to be explored, copulas being a candidate for such a development (e.g. Singh and Zhang, 2007; Ariff et al., 2012).

It is also envisioned to test other IDAF model formulations based on alternative approaches for modelling the scale relationships, among which the method proposed by Overeem et al. (2010) seems of particular interest. 


\section{Appendix A}

A brief explanation of the transition between the simplescaling framework used to described the space-time scaling of maximum annual rainfall (Eq. 13) and the GEV model used to model the statistical distribution of these maxima (Eqs. 15 to 17) is given here.

The random variables $I\left(D_{\text {ref }}, 0\right)$ and $I(D, A)$ are modelled by a GEV model:

$\operatorname{Prob}\left\{I\left(D_{\text {ref }}, 0\right) \leq i\left(D_{\text {ref }}, 0\right)\right\}=$

$\exp \left\{-\left[1+\xi\left(D_{\mathrm{ref}}, 0\right)\left(\frac{i\left(D_{\mathrm{ref}}, 0\right)-\mu\left(D_{\mathrm{ref}}, 0\right)}{\sigma\left(D_{\mathrm{ref}}, 0\right)}\right)\right]^{-\frac{1}{\xi\left(D_{\mathrm{ref}}, 0\right)}}\right\}$

and

$\operatorname{Prob}\{(I(D, A) \leq i(D, A)\}$

$=\exp \left\{-\left[1+\xi(D, A)\left(\frac{i(D, A)-\mu(D, A)}{\sigma(D, A)}\right)\right]^{-\frac{1}{\xi(D, A)}}\right\}$.

Letting $c=\lambda^{\eta} \times \operatorname{ARF}(D, A)$, then Eq. (13) becomes

$I(D, A) \stackrel{d}{=} I\left(D_{\mathrm{ref}}, 0\right) \times c$

and if Eq. (13) holds, then

$\operatorname{Prob}\{I(D, A) \leq i(D, A)\}$

$$
\begin{aligned}
& =\operatorname{Prob}\left\{I\left(D_{\text {ref }}, 0\right) \times c \leq i\left(D_{\text {ref }}, 0\right) \times c\right\} \\
& =\operatorname{Prob}\left\{I\left(D_{\text {ref }}, 0\right) \leq i\left(D_{\text {ref }}, 0\right)\right\}
\end{aligned}
$$

and
$\operatorname{Prob}\{I(D, A) \leq i(D, A)\}$

$=\exp \left\{-\left[1+\xi\left(D_{\mathrm{ref}}, 0\right)\left(\frac{i\left(D_{\mathrm{ref}}, 0\right)-\mu\left(D_{\mathrm{ref}}, 0\right)}{\sigma\left(D_{\mathrm{ref}}, 0\right)}\right)\right]^{-\frac{1}{\xi\left(D_{\mathrm{ref}}, 0\right)}}\right\}$.

By replacing $I\left(D_{\text {ref }}, 0\right)$ by $I(D, A) / c$ we obtain

$\operatorname{Prob}\{I(D, A) \leq i(D, A)\}$

$=\exp \left\{-\left[1+\xi\left(D_{\mathrm{ref}}, 0\right)\left(\frac{\frac{I(D, A)}{c}-\mu\left(D_{\mathrm{ref}}, 0\right)}{\sigma\left(D_{\mathrm{ref}}, 0\right)}\right)\right]^{-\frac{1}{\xi\left(D_{\mathrm{ref}}, 0\right)}}\right\}$

or

$\operatorname{Prob}\{I(D, A) \leq i(D, A)\}$

$=\exp \left\{-\left[1+\xi\left(D_{\mathrm{ref}}, 0\right)\left(\frac{I(D, A)-\mu\left(D_{\mathrm{ref}}, 0\right) \times c}{\sigma\left(D_{\mathrm{ref}}, 0\right) \times c}\right)\right]^{-\frac{1}{\xi\left(D_{\mathrm{ref}}, 0\right)}}\right\}$.

The equality between Eq. (A2) and Eq. (A7) gives

$$
\begin{aligned}
& \mu(D, A)=\mu_{\text {ref }} \times c \\
& \sigma(D, A)=\sigma_{\text {ref }} \times c \\
& \xi(D, A)=\xi_{\text {ref }} .
\end{aligned}
$$

Equations (A8)-(A10) correspond to Eqs. (15)-(17) in the main text. 
Acknowledgements. This research was partly funded by the LABEX OSUG@2020 (ANR10 LABX56), partly by the French project ESCAPE (ANR10-CEPL-005), and partly by IRD and INSU through the support to the AMMA-CATCH observing system. Gérémy Panthou's Ph.D. grant is funded by SOFRECO.

Edited by: P. Molnar

\section{References}

Ali, A., Lebel, T., and Amani, A.: Invariance in the Spatial Structure of Sahelian Rain Fields at Climatological Scales, J. Hydrometeorol., 4, 996-1011, 2003.

Allen, R. and DeGaetano, A.: Areal Reduction Factors for Two eastern United States Regions with High Rain-Gauge Density, J. Hydrol. Eng., 10, 327-335, 2005.

Ariff, N., Jemain, A., Ibrahim, K., and Wan Zin, W.: IDF relationships using bivariate copula for storm events in Peninsular Malaysia, J. Hydrol., 470-471, 158-171, 2012.

Asquith, W. H. and Famiglietti, J. S.: Precipitation areal-reduction factor estimation using an annual-maxima centered approach, J. Hydrol., 230, 55-69, 2000.

Awadallah, A.: Developing Intensity-Duration-Frequency Curves in Scarce Data Region: An Approach using Regional Analysis and Satellite Data, Engineering, 03, 215-226, 2011.

Bara, M., Kohnová, S., Gaál, L., Szolgay, J., and Hlavcoá, K.: Estimation of IDF curves of extreme rainfall by simple scaling in Slovakia, Contributions to Geophysics and Geodesy, 39, 187206, 2009.

Bell, F.: The areal reduction factor in rainfall frequency estimation, Tech. rep. 35, Institute of hydrology, Natural Environment Research Council, UK, 1976.

Ben-Zvi, A.: Rainfall intensity-duration-frequency relationships derived from large partial duration series, J. Hydrol., 367, 104-114, 2009.

Bendjoudi, H., Hubert, P., Schertzer, D., and Lovejoy, S.: Interprétation multifractale des courbes intensité-duréé-fréquence des précipitations, C. R. Acad. Sci. Paris, Sciences de la terre et des planétes/Earth \& Planetary Sciences, 325, 323-326, 1997.

Borga, M., Vezzani, C., and Fontana, G. D.: Regional rainfall depthduration-frequency equations for an Alpine region, Natural Hazards, 36, 221-235, 2005.

Burlando, P. and Rosso, R.: Scaling and muitiscaling models of depth-duration-frequency curves for storm precipitation, J. Hydrol., 187, 45-64, 1996.

Castro, J. J., Cârsteanu, A. A., and Flores, C. G.: Intensityduration-area-frequency functions for precipitation in a multifractal framework, Physica A: Statistical Mechanics and its Applications, 338, 206-210, 2004.

Ceresetti, D.: Structure spatio-temporelle des fortes précipitations: Applicatio á la région Cévennes Vivarais, Ph.D. thesis, Université de Grenoble, 2011.

Ceresetti, D., Anquetin, S., Molinié, G., Leblois, E., and Creutin, J.: Multiscale Evaluation of Extreme Rainfall Event Predictions Using Severity Diagrams, Weather Forecast., 27, 174-188, 2011.

Coles, S.: An introduction to statistical modeling of extreme values, Springer, London; New York, 2001.
De Michele, C., Kottegoda, N. T., and Rosso, R.: The derivation of areal reduction factor of storm rainfall from its scaling properties, Water Resour. Res., 37, 3247-3252, 2001.

De Michele, C., Kottegoda, N., and Rosso, R.: IDAF (intensityduration-area frequency) curves of extreme storm rainfall: a scaling approach, Water Sci. Technol., 45, 83-90, 2002.

De Michele, C., Zenoni, E., Pecora, S., and Rosso, R.: Analytical derivation of rain intensity-duration-area-frequency relationships from event maxima, J. Hydrol., 399, 385-393, 2011.

Descroix, L., Genthon, P., Amogu, O., Rajot, J. L., Sighomnou, D., and Vauclin, M.: Change in Sahelian Rivers hydrograph: The case of recent red floods of the Niger River in the Niamey region, Global Planet. Change, 98-99, 18-30, 2012.

Di-Baldassarre, G., Montanari, A., Lins, H., Koutsoyiannis, D., Brandimarte, L., and Böschl, G.: Flood fatalities in Africa: From diagnosis to mitigation, Geophys. Res. Lett., 37, 1-5, 2010.

Gerold, L. and Watkins, D.: Short Duration Rainfall Frequency Analysis in Michigan Using Scale-Invariance Assumptions, J. Hydrol. Eng., 10, 450-457, 2005.

Gupta, V. and Waymire, E.: Multiscaling properties of spatial rainfall and river flow distributions, J. Geophys. Res., 95, 1999-2009, 1990.

Hosking, J. and Wallis, J. R.: Regional frequency analysis: an approach based on L-moments, Cambridge University Press, Cambridge UK, 1997.

Koutsoyiannis, D., Kozonis, D., and Manetas, A.: A mathematical framework for studying rainfall intensity-duration-frequency relationships, J. Hydrol., 206, 118-135, 1998.

Lebel, T., Sauvageot, H., Hoepffner, M., Desbois, M., Guillot, B., and Hubert, P.: Rainfall estimation in the Sahel: the EPSATNIGER experiment, Hydrol. Sci., 37, 201-215, 1992.

Menabde, M., Seed, A., and Pegram, G.: A simple scaling model for extreme rainfall, Water Resour. Res., 35, 335-339, 1999.

Mohymont, B., Demarée, G. R., and Faka, D. N.: Establishment of IDF-curves for precipitation in the tropical area of Central Africa - comparison of techniques and results, Nat. Hazards Earth Syst. Sci., 4, 375-387, doi:10.5194/nhess-4-375-2004, 2004.

Nhat, L., Tachikawa, Y., Sayama, T., and Takara, K.: A simple scaling charateristics of rainfall in time and space to derive intensity duration frequency relationships, Annu. J. Hydraul. Eng., 51, 7378, 2007.

Overeem, A., Buishand, A., and Holleman, I.: Rainfall depthduration-frequency curves and their uncertainties, J. Hydrol., 348, 124-134, 2008.

Overeem, A., Buishand, T. A., and Holleman, I.: Extreme rainfall analysis and estimation of depth-duration-frequency curves using weather radar, Water Resour. Res., 45, W10424, doi:10.1029/2009WR007869, 2009.

Overeem, A., Buishand, T. A., Holleman, I., and Uijlenhoet, R.: Extreme value modeling of areal rainfall from weather radar, Water Resour. Res., 46, W09514, doi:10.1029/2009WR008517, 2010.

Oyebande, L.: Deriving rainfall intensity-duration-frequency relationships and estimates for regions with inadequate data, Hydrol. Sci. J., 27, 353-367, 1982.

Oyegoke, S. and Oyebande, L.: A new technique for analysis of extreme rainfall for Nigeria, Environ. Res. J., 2, 7-14, 2008.

Panthou, G., Vischel, T., Lebel, T., Blanchet, J., Quantin, G., and Ali, A.: Extreme rainfall in West Africa: A regional modeling, Water Resour. Res., 48, 1-19, 2012. 
Panthou, G., Vischel, T., Lebel, T., Quantin, G., Pugin, A.-C., Blanchet, J., and Ali, A.: From pointwise testing to a regional vision: An integrated statistical approach to detect nonstationarity in extreme daily rainfall. Application to the Sahelian region, J. Geophys. Res.-Atmos., 118, 8222-8237, 2013.

Papalexiou, S. and Koutsoyiannis, D.: Battle of extreme value distributions: A global survey on extreme daily rainfall, Water Resour. Res., 49, 187-201, 2013.

Ribstein, P. and Rodier, J.: La predetermination des crues sur des petits bassins saheliens inferieurs à $10 \mathrm{~km}^{2}$, Tech. rep., ORSTOM, Laboratoire d'hydrologie, Montpellier, 1994.

Rodier, J. and Ribstein, P.: Estimation des caracteristiques de la crue decennale pour les petits basins versants du Sahel couvrant de 1 a $10 \mathrm{~km}^{2}$, Tech. rep., ORSTOM, Laboratoire d'hydrologie, Montpellier, 1988 .

Samimi, C., Fink, A. H., and Paeth, H.: The 2007 flood in the Sahel: causes, characteristics and its presentation in the media and FEWS NET, Nat. Hazards Earth Syst. Sci., 12, 313-325, doi:10.5194/nhess-12-313-2012, 2012.

Schertzer, D. and Lovejoy, S.: Physical Modeling and Analysis of Rain and Clouds by Anisotropic Scaling Multiplicative Processes, J. Geophys. Res., 92, 9693-9714, 1987.

Singh, V. and Zhang, L.: IDF Curves Using the Frank Archimedean Copula, J. Hydrol. Eng., 12, 651-662, 2007.
Soro, G., Goula, B. T. A., Kouassi, F., and Srohourou, B.: Update of Intensity-Duration-Frequency curves for precipitation of short durations in tropical area of West Africa (cote d'Ivoire), J. Appl. Sci., 10, 704-715, 2010.

Tarhule, A.: Damaging Rainfall and Flooding: The Other Sahel Hazards, Climatic Change, 72, 355-377, 2005.

Van-de Vyver, H. and Demarée, G. R.: Construction of IntensityDuration-Frequency (IDF) curves for precipitation at Lubumbashi, Congo, under the hypothesis of inadequate data, Hydrological Sciences Journal - Journal des Sciences Hydrologiques, $55,555-564,2010$.

Veneziano, D. and Langousis, A.: The areal reduction factor: A multifractal analysis, Water Resour. Res, 41, W07008, doi:10.1029/2004WR003765, 2005.

Veneziano, D., Furcolo, P., and Iacobellis, V.: Imperfect scaling of time and space-time rainfall, J. Hydrol., 322, 105-119, 2006.

Vischel, T., Quantin, G., Lebel, T., Viarre, J., Gosset, M., Cazenave, F., and Panthou, G.: Generation of High-Resolution Rain Fields in West Africa: Evaluation of Dynamic Interpolation Methods, J. Hydrometeorol., 12, 1465-1482, 2011.

Yu, P., Yang, T., and Lin, C.: Regional rainfall intensity formulas based on scaling property of rainfall, J. Hydrol., 295, 108-123, 2004. 